\title{
Pharmacology and Phytochemistry of Isoflavonoids from Iris Species
}

\author{
Disha Choudhary and Afroze Alam*1,2,3 \\ ${ }^{1}$ Institute of Pharmacy, Shri Jagdish Prasad Jhabarmal Tibrewala University, India \\ ${ }^{2}$ Narayan Institute of Pharmacy, India \\ ${ }^{3}$ School of Pharmacy, Shoolini University, India
}

Submission: June 16, 2016; Published: July 13, 2017

*Corresponding author: Afroze Alam, Narayan Institute of Pharmacy, Jamuhar, Sasaram (Rohtas)-821305(Bihar)-India, Tel: 918091974886;

Fax: +91612226267; Email: afrozepharma@gmail.com; afrozalam@niop.in

Abstract

Iris is the largest and most complicated genus of family Iridaceae. Irises are mainly used as the ornamental plants, due to their colorful flowers, or in the perfume industry, due to their violet like fragrance, but lot of iris species were also used in many part of the worlds as medicinal plants for healing of a wide spectrum of diseases. The phytochemical investigations of various species of iris have resulted in the isolation of variety of secondary metabolites. Approximately more than two hundred compounds have been reported from the genus iris which includes flavonoids, isoflavonoids and their glycosides, benzoquinones triterpenoids and stilbenes glycosides.

This genus is rich in isoflavonoids which have a wide range of biological activity including anti-inflammatory, antioxidant and cancer chemo preventive properties. Nowadays phytochemical and pharmacological investigations bring new knowledge about chemical compounds in roots, leaves and flowers of the Iris species, about their chemical content and possible pharmacological and medicinal usage. This review brings together results of the iris research in last few decades, putting together the information about the isolation of isoflavones and their associated pharmacological activities. The reviews also signify the direct benefits of consumption of isoflavone rich-diet and reduction of various diseases such as cancer, cardiovascular disorder, and osteoporosisor against the bacterial and viral infections.

Keywords: Cancer; Glycoside; Isoflavone; Iris species; Osteoporosis; Phytochemical investigation

\section{Introduction}

\section{General Introduction}

Isoflavones are the most well-known of the phytoestrogens isolated from various species of Iris. The recognition of 'clover disease' in Australian sheep in the 1940s led to the investigation of estrogenic activity of isoflavones [1]).The sheep whose diet was predominately subterranean clover (Trifolium subterraneum L., Fabaceae) suffered from a reproductive disorder that reduced the lambing rates and involved abnormal lactation, changes in the sex organs, permanent infertility, prolapsed uterus and maternal dystocia [2] Isoflavones constitute the largest group of natural isoflavonoids with large number of new structures reported in every year. The occurrence of isoflavonoids in plants of traditional medicine has promoted the increasing interest in the search for biologically active constituents from both legume and non-legume sources specially Iridaceae [3]. Isoflavones found in the family Iridaceae, in particular Iris species have a characteristic 5, 6, 7-trioxygenation pattern [4] (Figure 1) (Table 1).

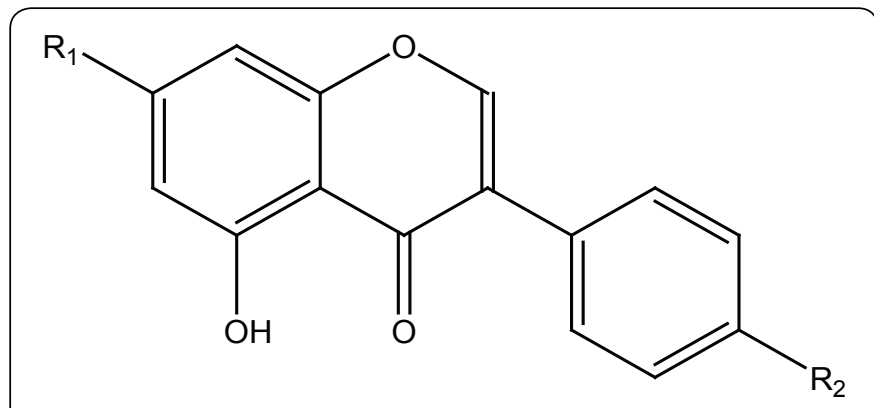

Figure 1: Common structure of Isoflavones.

Table 1: Different Substitutions of natural isoflavone.

\begin{tabular}{|c|c|c|}
\hline Isoflavones & $\mathbf{R}_{\mathbf{1}}$ & $\mathbf{R}_{\mathbf{2}}$ \\
\hline Daidzein & $\mathrm{H}$ & $\mathrm{OH}$ \\
\hline Genistein & $\mathrm{OH}$ & $\mathrm{OH}$ \\
\hline Biochanin A & $\mathrm{OH}$ & $\mathrm{OCH}_{3}$ \\
\hline Formononetin & $\mathrm{H}$ & $\mathrm{OCH}_{3}$ \\
\hline
\end{tabular}




\section{Occurrence}

Most members of the Fabaceae family contain significant quantities of isoflavones. Analysis of levels in various species has found that the highest levels of genistein and daidzein in psoralea (Psoralea corylifolia). Various legumes including soybean (Glycine max L.), green bean (Phaseolus vulgaris L.), alfalfa sprout (Medicago sativa L.), mung bean sprout (Vigna radiata L.), cowpea (Vigna unguiculata L.), kudzu root (Pueraria lobata L.), and red clover blossom and red clover sprout (Trifolium pratense L.) have been studied for their estrogenic activity [5]. Highly processed foods made from legumes, such as tofu, retain most of their isoflavone content, with the exception of fermented miso, which has increased levels.Other dietary sources of isoflavones include chick pea (biochanin A), alfalfa (formononetin), and peanut (genistein) [6]. Isoflavones are also found in the Iridaceae family (Iris species).In plant tissue; they most often occur as glycosides or their respective malonates or acetyl conjugates, rendering them even more water-soluble [7].

Epidemiological studies indicating associations between diet and disease states led to the investigation of a series of bioactive plant compounds, called phytochemicals. Some of these nonnutrient plant chemicals, such as phytoestrogens were shown to confer significant long-term health benefits. Phytoestrogens are structurally and functionally similar to human estrogen. There are two types of phytoestrogens, the lignans and the isoflavones. Soybeans are especially rich in isoflavones. They contain the isoflavones genistein and daidzein and their respective $\beta$ glycosides genistin and daidzin. We herein report the use of this aglycone (Isoflavone) as a versatile molecule isolated from Iris species.

\section{Phytochemistry of Isoflavones}

The presence of isoflavones in rhizomes or aerial parts is one of the most distinctive chemical features of the genus Iris [8]. One of the earliest reports on this genus was of the isoflavones irigenin and its 7-glucoside iridin in orris root, of Iris florentina. Their chemical structures were determined by Baker [9]. The isoflavone irigenin has a unique substitution pattern, which is rarely observed outside Iris. Within Iris, irigenin is frequently accompanied by one or more related structures but particularly by tectorigenin, first obtained from I. tectorum Maxim. Some thirty other isoflavones have been described variously from Iris species. A recent review described several new structures from Iris japonica Thunb (aerial parts), I. nigricans Dinsm. (rhizomes) and I. kashmiriana Baker(rhizomes) [10]. Finally, it should be emphasized that isoflavones, while occurring in the Leguminosae and at least a dozen other dicotyledonous families, are relatively rare in the monocotyledons. There are only two reports outside the Iridaceae, in Festuca L.(Gramineae) and Hemerocallis L. (now Hemerocallidaceae) [11] (Figure 2). The unique structural pattern associated with the isoflavones prompted us to undertake the phytochemical investigation of these molecules mainly isolated from Iris species [12], which are reported to be a rich source of isoflavones.

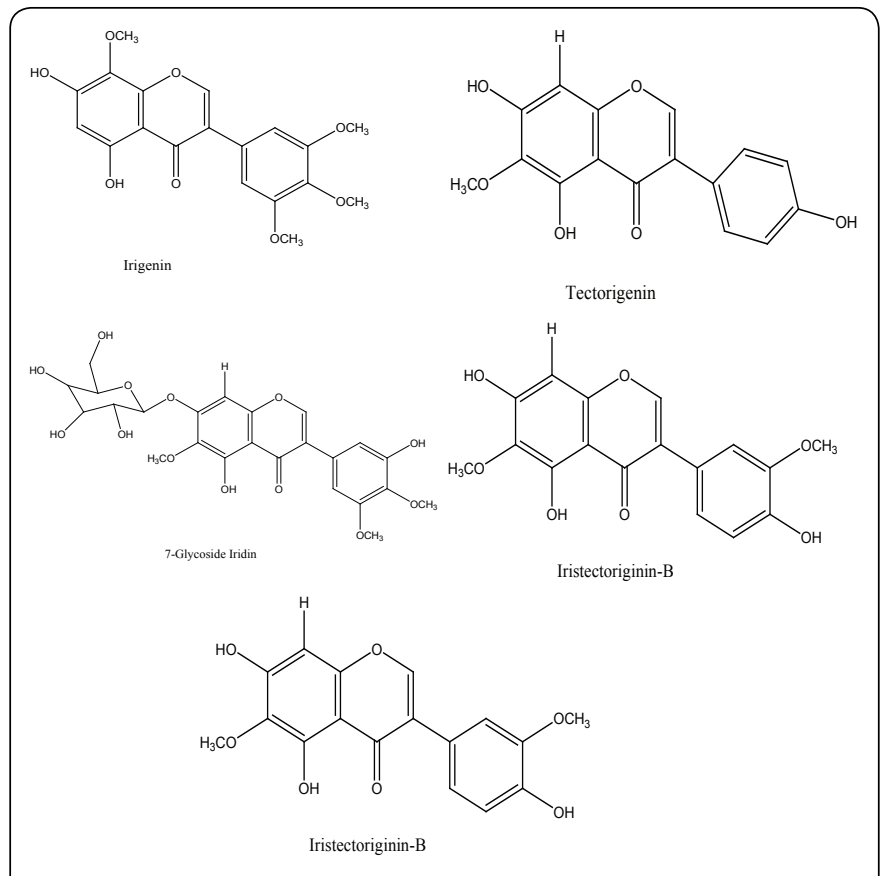

Figure 2: Structure of Isoflavone from different Iris species.

\section{Pharmacology of Isoflavones}

Antioxidant and Antimicrobial (Antibacterial and Antifungal) Activity of isoflavones: Rigano Det al. [13] explained theantioxidant activity of isoflavonoids and flavonoids from rhizomes of Iris pseudopumila. Chromatographic separation of a methanolic extract from Iris pseudopumila rhizomes led to the isolation of two new natural compounds, irilone and isoscutellarein, along with 9 isoflavonoids and 4 flavonoids. Their structures were determined on the basis of spectroscopic evidence. Isolated compounds were evaluated for their antioxidant activity using the luminol-dependent chemiluminescence assay, with quercetin as a positive control. Irilone and kaempferol showed significant antioxidant activity [13]. Rigano Det al. [14] explained comparative free radical scavenging potential and cytotoxicity of different extracts from Iris pseudopumila Tineo flowers and rhizomes.

The aim of this study was to evaluate the in vitro antioxidant and cytotoxic activities of different extracts from Iris pseudopumila Tineo flowers and rhizomes. The radical scavenging activity was assessed by means of DPPH assay. The antioxidant activity was assessed by means of two tests: bleaching of $\beta$-carotene and lipid peroxidation of liposomes. Methanolic and chloroform extracts from the flowers of I. pseudopumila showed a significant antiradical effect with $\mathrm{IC}_{50}$ of 101 and $83 \mu \mathrm{g} \mathrm{mL} \mathrm{L}^{-1}$, respectively. As regards to lipid peroxidation, the best activity was showed by methanolic extract of flowers $\left(\mathrm{IC}_{50}\right.$ of $18 \mu \mathrm{g} \mathrm{mL} \mathrm{L}^{-1}$ ) and chloroform extract of rhizomes $\left(\mathrm{IC}_{50} 33 \mu \mathrm{g} \mathrm{mL}^{-1}\right.$ ). The cytotoxic activity was carried out using the Sulforhodamine B (SRB) 
assay. The chloroform extract from rhizomes demonstrated a good cytotoxic activity against amelanotic melanoma cancer

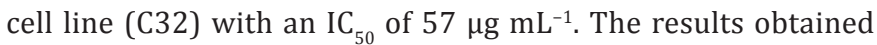
support the ethno medical claims for the plant. Al-Khateebet al [15], investigated antioxidant and antimicrobial activities of Iris nigricance methanolic extract containingphenolic compounds.

It has been observed from results that the flowers extract of Iris nigricans have the highest radical scavenging activity with the lowest IC50 value of $2.549 \mu \mathrm{g} / \mathrm{ml}$ followed by the leaves extracts with an IC50 value of $26.436 \mu \mathrm{g} / \mathrm{ml}$. While the rhizomes extracts have the lowest radical scavenging activity with an IC50 value of $40.064 \mu \mathrm{g} / \mathrm{ml}$. The results indicated that the antioxidant activity of flowers extract was higher than ascorbic acid and the other crude extracts. The phytochemical analysis of different parts of Iris nigricans (rhizomes, leaves and flowers) extracts indicated the presence of major phytocompounds as phenolic compounds (xanthones isoflavonoids and flavonoids) and acids, which might be responsible for the antioxidant activity. Preliminary antibacterial and antifungal activities of methanolic extracts of Iris nigricans (rhizomes, leaves and flowers) were evaluated. The leaf extract have showed promising antibacterial activity amongst all. These activities may be attributed to the presence of phenolic components (Isoflavone, Flavonoids and Xanthones) which can disrupt the cell membranes or inhibit the synthesis of certain enzymes [15].

Antifungal Activity: The antifungal activity of methanolic extracts of Iris nigricans (rhizomes, leaves and flowers) were screened and observed that leaves extract shows stronger antifungal activity than rhizomes and flowers extracts. The inhibition zone of leaves extract against Candida albicans was $15 \mathrm{~mm}$ while the inhibition zone of the well-known antifungal agent nystatin that was $17 \mathrm{~mm}$. Therefore, the antifungal activity of leaves extract was comparable to that of nystatin [15]. Ilyas et al (2012) proposed free radical scavenging and antibacterial activity of essential oil and solvent extracts of Iris planifolia (Mill) was investigated. The essential oil was analyzed by Gas chromatography mass spectrometry (GC-MS) and a total of 38 types of volatile organics were identified. The essential oil consists chiefly of alkanes (36.5\%), acids (19.1\%), ketones (11.7\%), alcohols (9.0\%), arylpropanoids (6.8\%) and aldehydes $(4.1 \%)$ accompanied by relatively much smaller amounts of monoterpenes (1.0\%). The antimicrobial activity of essential oil and ethanolic extract shows an important activity against Salmonella typhimuriumand Klebsiella pneumonia with minimum inhibitory concentration (MIC) of $3.12 \mathrm{mg} / \mathrm{ml}$. Furthermore, the free radical scavenging assay of the essential oil and extracts were determined using a 2,2-diphenyl-1-picrylhydrazyl (DPPH) test system.

The dichloromethane and water extract possessed strong radical scavenging activity with the lowest $\mathrm{IC}_{50}$ value of $0.1 \mathrm{mg} /$ $\mathrm{ml}$ followed by the aqueous extract with an $\mathrm{IC}_{50}$ value of $0.12 \mathrm{mg} /$ $\mathrm{ml}$. Phytochemical analysis revealed the presence of isoflavone, flavonoids, terpenoids, saponins, alkaloids and tannins which may be responsible for antimicrobial and antioxidant activities [16]. Ramtin et al [17], In Vitro antimicrobial activity of Iris pseudacorus In this study, the effects of antibacterial activity of Iris pseudacorus essential oils, native plant northern of Iran, were investigated for some selected bacteria The influence of essential oils was tested by the using of disk diffusion and micro-broth dilution methods against standard strains of the picked out bacteria. Minimum inhibitory concentrations (MIC) and minimum bactericidal concentration (MBC) of essential oils were utilized for this goal [17].

Rigano D et al. [18] investigated antibacterial and allopathic activity of methanolic extract from Iris pseudopumila rhizomes. Did "Antimicrobial screening of Iris aitchisonii (Bakar) Boiss" The present study was an attempt to verify the ethno botanical knowledge of Iris aitchisonii (Bakar) Boiss, a local plant, on scientific lines by evaluating the antimicrobial activity including Minimum Inhibitory Concentration (MIC) of its crude extracts. The plant material after its collection was subjected to maceration for obtaining its crude extracts in petroleum ether, chloroform, methanol and water. The results indicated highest antibacterial and antifungal potential, i.e. $45 \pm 1.73 \mathrm{~mm}$ and $57 \pm 1.0 \mathrm{~mm}$ against Pseudomonas aeruginosa and Aspergillus niger respectively. MIC value of the methanolic extract against Staphylococcus aureus and Pseudomonas aeruginosa was $0.002 \mu \mathrm{g} / \mathrm{mL}$ [19].

Anti-proliferative Activity: Afroze et al. (2017) reported two new glycosides and related isoflavonoids from Iris kashmiriana Baker and subjected to structure elucidation followed by their biological evaluation. Isolated compounds were characterized and identified by a combination of various spectroscopic technique vis. UV, IR, ${ }^{1} \mathrm{H} N M R,{ }^{13} \mathrm{C}$ NMR, DEPT, 2-D NMR and mass spectrometry coupled with chemical analysis. Furthermore, an in silico library of isolated isoflavones and its analogues were designed. NFkappa B (transcription factor that facilitates angiogenesis, inflammation, invasion and metastasis) was selected as a target to evaluate the anticancer and antioxidant activity of isoflavones and its analogues. The cell cycle specificity of the cytotoxicity was further analyzed by corresponding analysis, using flow cytometer.

Most of the compounds exhibit moderate activity, whereas the 5,7,8-trihydroxy-3-(4-methoxyphenyl)-4H-chromen-4-one,5,7,8trihydroxy-3-(4-hydroxyphenyl)-4H-chromen-4-one, 5, 7,8triacetoxyoxy-3-(4-methoxyphenyl)-4H-chromen-4-one and 6,7-diacetoxyoxy-3-(4-methoxyphenyl)-4H-chromen-4-one showed distinct broad-spectrum anticancer activity with $\mathrm{IC}_{50}$ values ranges between 3.8 and $5.6 \mathrm{mg} / \mathrm{mL}$. Cell cycle analysis indicates that these compounds induced cell cycle arrest at G2/M phase [8] (Figure 3(A \& B)). 


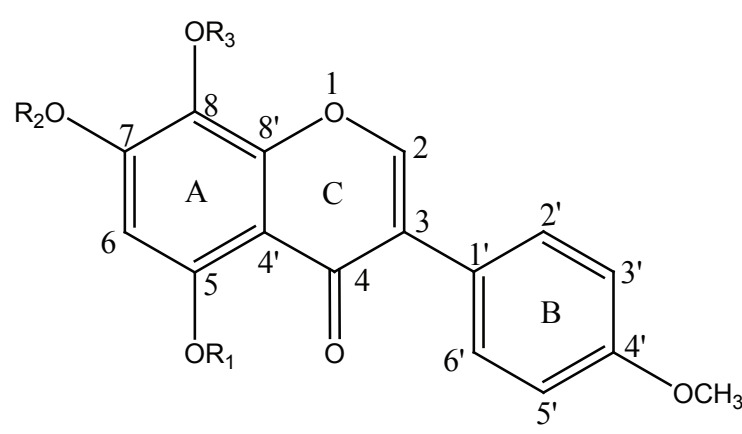

Figure 3(A): Glycoside-l.

1) $R_{1}=H, \quad R_{2}=$ Glu, $R_{3}=H$; 1a) $R_{1}=-O C O C H 3, R_{2}=$ Glu, $R_{3}=$ $\mathrm{OCOCH}_{3}$;

1b) $R_{1}, R_{2}, R_{3}=H$; 1c) $R_{1}, R_{2}, R_{3}=O O O_{3}$; 1d) $R_{1}=O_{3} H_{3} R_{2}=G l u$ $\mathrm{R}_{3}=\mathrm{OCH}_{3}$

1e) $\mathrm{R}_{1}=\mathrm{OCH}_{3} ; \mathrm{R}_{2}=-\mathrm{OH}, \mathrm{R}_{3}=\mathrm{OCH}_{3} ;$ 1f ) $\mathrm{R}_{1}=\mathrm{OCH}_{3} ; \mathrm{R}_{2}=\mathrm{OCOCH}_{3}$ $\mathrm{R}_{3}=\mathrm{OCH}_{3}$

1g) $R_{1}, R_{2}, R_{3}=H ; O_{3}=O H, \quad$ Glu= Glucose.

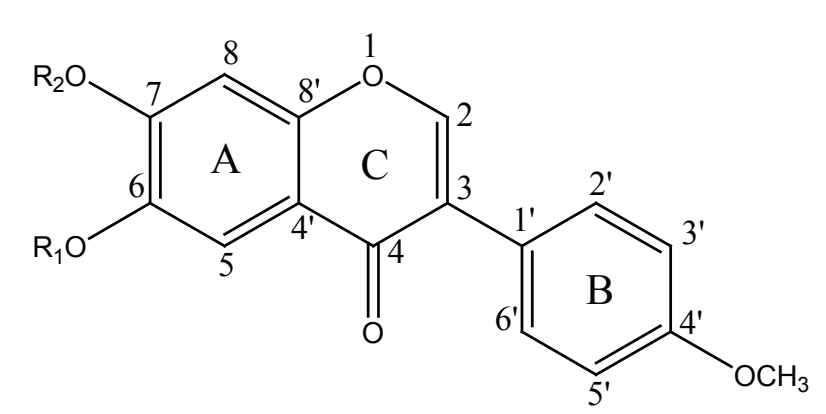

Figure 3(B): Glycoside-II.

2) $\left.\left.R_{1}=H, R_{2}=G l u, 2 a\right) R_{1}=-C_{3} C_{3}, R_{2}=H \quad 2 b\right) R_{1}, R_{2}$, = - $\left.-C_{3} C O C H_{3} 2 c\right)$ $\mathrm{R}_{1}, \mathrm{R}_{2}=\mathrm{H}$

2d) $\left.\left.\mathrm{R}_{1}=\mathrm{CH}_{3} ; \mathrm{R}_{2}=\mathrm{Glu}, 2 \mathrm{e}\right) \mathrm{R}_{1}=\mathrm{CH}_{3} ; \mathrm{R}_{2}=\mathrm{H}, 2 \mathrm{f}\right) \mathrm{R} 1=\mathrm{CH}_{3} ; \mathrm{R}_{2}=-\mathrm{OCOCH}_{3}$ Glu $=$ Glucose

Figure 3(A,B): Structure of glycoside - I\&II and their aglycones (Isoflavones)

Conforti et al. [20], reported anti-proliferative activity on human cancer cell lines after treatment with polyphenolic compounds isolated from Iris pseudopumila flowers and rhizomes. The study described the anti-proliferative properties of Iris pseudopumila flowers and rhizomes extracts and fourteen constituents isolated from them. The In Vitro cytotoxic activity assay against two human cancer cell lines, large lung carcinoma (CORL-23) and amelanotic melanoma (C32), showed that the most anti-proliferative extract was the $\mathrm{MeOH}$ extract from flowers with a percentage of inhibition of 50.9 at $100 \mu \mathrm{g} / \mathrm{ml}$ against amelanotic melanoma cells. The most anti-proliferative compounds against amelanotic melanoma cells were kaempferol3-0- $\beta$-D-glucopyranoside and Irisolidone with a percentage of inhibition of 100 and 96.6, respectively, and against large lung carcinoma cells with a percentage of inhibition of 82.1 and 84.6, respectively. Significant activity on the amelanotic melanoma cell line was also showed by irigenin-7-0- $\beta$-D-glucopyranoside, with a percentage of inhibition of 89.3. The compounds isovitexin and isoorientin-6-0"- $\beta$-D-glucopyranoside showed a selective activity against amelanotic melanoma cells with a percentage of inhibition of 83.2 and 79.8, respectively [20]. Wollenweberet al. [21] described "Cancer Chemopreventive In Vitro Activities of Isoflavones Isolated from Iris germanica". Six known isoflavones were isolated from rhizome of Iris germanica, [21]. These compounds were examined for their cancer chemopreventive potential. They were shown to be potent inhibitors of cytochrome P 450 IA activity with $\mathrm{IC}_{50}$ value in the range 0.25-4.9 $\mu \mathrm{M}$.

Isoflavones as phytohormones and phytosterols: Isoflavones have the phenyl group attached to the 3 -position, whereas in flavones the phenyl group is attached to the 2-position. The isoflavones are mainly found to occur within the Leguminosae (specifically in the sub-family Papilionoideae), although the literature shows many other species that contain these chemical moieties Isoflavones are also found in other botanical families such as the Compositae, the Iridaceae, the Myristicaceae, and the Rosaceous. These isoflavones can act as steroidal mimics by filling the stereochemical space that could be occupied by oestrogenic compounds. It is this special chemistry that helps explain the effects of many nutritional herbal supplements and topical preparations [22]. The Figure 4 shows daidzein in ER Receptor [23].

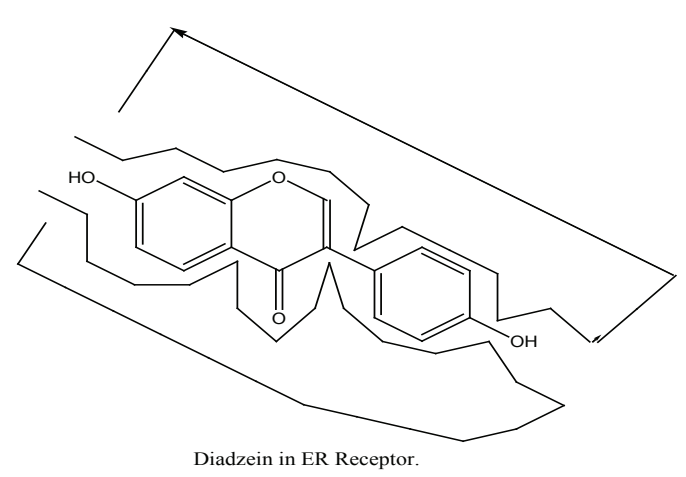

Figure 4: Diazdein in active site of the ER receptor.

Anti-osteoporotic activity: Jung-Lye Kim et al. [24] reported osteogenic activity of Yellow Flag Iris (Iris pseudacorus) Extract Modulating Differentiation of Osteoblasts and Osteoclasts. This study investigated the yellow flag Iris extract (YFIE) and revealed its anti-osteoporotic effects in osteoblastic MC3T3-E1 mouse cells and RAW 264.7 murine macrophages. When osteoblasts were treated with 1-20 $\mu \mathrm{g} / \mathrm{ml}$ YFIE in an osteogenic medium, the bone nodule formation by calcium deposits was markedly enhanced during differentiation. Consistently, YFIE stimulated alkaline phosphatase activity and collagen type I secretion with a substantial effect on osteoblast proliferation [24] (Figure 4).

Immunomodulatory activity: Nazir et al. [25] Showed immunomodulatory activityof isoflavone isolated from Iris germanica (Iridaceae) on T-lymphocytes and cytokines. 
The immunomodulatory activities of two isoflavones, 5,7-dihydroxy-6,4'-dimethoxyisoflavone (Irisolidone) (1) and 5,4'-dihydroxy-6,7-methylenedioxyisoflavone (irilone) (2) isolated from Iris germanica (Iridaceae) was reported. Their influence on production of T-lymphocytes (CD4+ and CD8+ cells) and T-cell cytokines, namely Th1: IL-2, IFN-gamma and Th2: IL-4 and IL-5 in a dose-dependent manner was studied by flow cytometric method in Balb/c mice. Oral administration of drugs at doses of 0.1-0.8 mg/ $\mathrm{kg}$ per oral dose showed 1 to possess stimulatory activity on T-cells and Th1 cytokine production, while as 2 acted as an immunosuppressant for both cells and cytokines. The methylated products of 1 and 2 showed a similar trend to that of their parent compounds but their activity was drastically decreased revealing the importance of free phenolic groups for their immunomodulatary activities [25].

Traditional and Economical Importance of Genus Iris: Several cultures have used species of Iris as food, ornamental, condimental, or medicinal plants. The Navajo, the largest Native American tribe of North America, used decoctions of Iris missouriensis as an emetic [26] Pieces of the rhizome of the same species were used to relieve toothaches, or earaches [27]. The mashed roots of Iris versicolor were applied to wounds, presumably as an antiseptic and the infusions of dry roots of the same species were used to calm pain. Leaves or leaf-sap were used as a dye, to give the blue color to tattoos. The use of the leaves, macerated with salt, sugar, and other spices was recommended to clean the skin and cure skin diseasesx [28]. Iris ensata was used in India as anthelmintic and diuretic, and, mixed with other species, to treat venereal diseases [29]. Iris species are of considerable economic importance in ornamental horticulture and the cut-flower industry, especially Irisgladiolus, and Irisfreesia. Several other genera (e.g., Crocus, Dietes, Sparaxis, Tritonia and Watsonia) are cultivated in gardens in both tropical and temperate areas. Moraea and Homeria are poisonous and pose significant problems in cattle- and sheep-raising areas, notably in southern Africa

\section{Conclusion}

Isoflavonoids and flavonoids are prominent plant secondary metabolites with variable phenolic structures and are consumed by humans as dietary constituents. Although not considered nutrients and thus essential for life, isoflavonoid ingestion may play a significant role in health and disease Numerous studies have shown an association between isoflavone-rich dietary consumption and reduced cancer risk, particularly breast and prostate cancers It has been shown that some isoflavones can act as inhibitors of the multidrug resistance transporter MRP1 by influencing the biophysical properties of membranes. The preventive role of isoflavones in cancer cardiovascular diseases, osteoporosis, and menopausal symptoms in addition to their antioxidant anti-inflammatory and estrogenic activities has been largely documented. The estrogenic activities of genistein, daidzen, and equol are currently being extensively investigated at the molecular, preclinical, and clinical levels to determine their potential for the treatment of chronic diseases such as hormonedependent cancer, cardiovascular diseases, and osteoporosis.

The wide spectrum of pharmacological activities associated with the isoflavones prompted us to compile a review on phytochemical and pharmacological investigations on various biological activities of various plants which are reported to be a rich source of isoflavones. In conclusion, there is no doubt that the Iris species contain a heterogeneous collection of isoflavone and related phenolic constituents. Many of these are potentially useful as taxonomic markers, but further detailed surveys are still needed to establish an exhaustive structural activity relationship as potent bioactive candidate.

\section{Acknowledgment}

The authors thank to Narayan Institute of Pharmacy and Narayan Medical College \& Hospital, Jamuhar-821305, Sasaram - Bihar (India). We also thank to School of Pharmaceutical Sciences Shoolini University, Solan, (H.P) to facilitate part of this work.

\section{References}

1. Ososki AL, Kennelly EJ (2003) Phytoestrogens: a review of the present state of research. Phytother Res 17(8): 845-869.

2. Bennetts HW, Uuderwood EJ, Shier FL (1946) A specific breeding problem of sheep on subterranean clover pastures in Western Australia. Aust Vet J 22(1): 2-12.

3. Glazier MG, Bowman MA (2001) A reviews of the evidence for the use of phytoestrogens as a replacement for traditional estrogen replacement therapy. Arch Intern Med 161(9): 1161-1172.

4. Woźniak D, Matkowski A (2015) Belamcandae chinensis rhizoma-a review of phytochemistry and bioactivity. Fitoterapia 107: 1-4.

5. Tsao R, Papadopoulos Y, Yang R, Young JC, McRae K (2006) Isoflavone profiles of red clovers and their distribution in different parts harvested at different growing stages. J Agric Food Chem 54(16): 5797-5805.

6. Friedman M, Brandon DL (2001) Nutritional and health benefits of soy proteins. J Agric Food Chem 49(3): 1069-1086.

7. Dillard CJ, German JB (2000) Phytochemicals: nutraceuticals and human health. J Sci Food Agric 80(12): 1744-1756.

8. Alam A, Jaiswal V, Akhtar S, Jayashree BS, Dhar KL (2017) Isolation of isoflavones from Iris kashmiriana Baker as potential anti proliferative agents targeting NF-kappaB. Phytochemistry 136: 70-80.

9. Lee SJ, Ahn JK, Khanh TD, Chun SC, Kim SL, et al. (2007) Comparison of isoflavone concentrations in soybean (Glycine max (L.) Merrill) sprouts grown under two different light conditions. J Agric Food Chem 55(23): 9415-9421.

10. Boland GM, Donnelly DM (1998) Isoflavonoids and related compounds. Nat Prod Rep 15(3): 241-260.

11. Umezawa T (2003) Diversity in lignan biosynthesis. Phytochem Rev 2(3): 371-390.

12. Michel T, Halabalaki M, Skaltsounis AL (2013) New concepts, experimental approaches, and dereplication strategies for the discovery of novel phytoestrogens from natural sources. Planta Med 79(7): 514-532. 
13. Rigano D, Formisano C, Basile A, Lavitola A, Senatore F, et al. (2007) Antibacterial activity of flavonoids and phenylpropanoids from Marrubium globosum ssp. libanoticum. Phytother Res 21(4): 395-397.

14. Rigano D, Conforti F, Formisano C, Menichini F, Senatore F (2009) Comparative free radical scavenging potential and cytotoxicity of different extracts from Iris pseudopumila Tineo flowers and rhizomes. Nat Prod Res 23(1): 17-25.

15. Al-Khateeb E, Finjan S (2013) Isolation and Identification of Some Phytochemical Compounds from Different Parts of Iris Nigricans. Eur Sci J 9(6): 213-218

16. Chikhi I, Allali H, Dib ME, Halla N, Muselli A, et al. (2012) Free radical scavenging and antibacterial activity of essential oil and solvent extracts of Iris planifolia (Mill) from Algeria. J Med Plan Res 6(10):1961-1968.

17. Ramtin M, Pahlaviani MR, Massiha A, Issazadeh K, Heidari S (2013) Comparative Evaluation of the Antibacterial Activities of Essential Oils of Iris pseudacorus and Urtica dioica Native North of Iran. J Pure Appl Microb 7(2): 1065-1670.

18. Rigano D, Grassia A, Formisano C, Basile A, Sorbo S, et al. (2006) Antibacterial and allelopathic activity of methanolic extract from Iris pseudopumila rhizomes. Fitoterapia 77(6): 460-462.

19. Ajaib MU, Khan Z, Abbasi MA, Riaz T (2013) Antimicrobial screening of Iris aitchisonii (Bakar) Boiss Biologia 59(1): 51-55.

20. Conforti F, Menichini F, Rigano D, Senatore F (2009) Antiproliferative activity on human cancer cell lines after treatment with polyphenolic compounds isolated from Iris pseudopumila flowers and rhizomes. Z Naturforsch C 64(7-8): 490-494.
21. Wollenweber E, Stevens JF, Klimo K, Knauft J, Frank N (2003) Cancer chemopreventive In Vitro activities of isoflavones isolated from Iris germanica. Planta Med 69(01): 15-20.

22. Dweck AC (2009) The internal and external use of medicinal plants. Clin Dermatol 27(2): 148-158.

23. Swann R, Perkins KA, Velentzis LS, Ciria C, Dutton SJ, et al. (2013) The Diet Comply study: A prospective cohort study of breast cancer survival and phytoestrogen consumption. Maturitas 75(3): 232-240.

24. Kim JL, Li HM, Kim YH, Lee YJ, Shim JH, et al. (2012) Osteogenic activity of yellow flag Iris (Iris pseudacorus) extract modulating differentiation of osteoblasts and osteoclasts. Am J Chin Med 40(6): 1289-1305.

25. Nazir N, Koul S, Qurishi MA, Taneja SC, Ahmad SF, et al. (2009) Immunomodulatory activity of isoflavones isolated from Iris germanica (Iridaceae) on T-lymphocytes and cytokines. Phytother Res 23(3): 428433.

26. Vestal PW (1952) Preoperative preparation of the skin with a depilatory cream and a detergent. The Am J Surg 83(3): 398-402.

27. Nickerson GS (1966) Some data on Plains and Great Basin Indian uses of certain native plants. Tebiwa 9(1): 45-51.

28. Rahmatullah M, Hasan A, Parvin W, Moniruzzaman M, Khatun A, et al. (2012) Medicinal plants and formulations used by the Soren clan of the Santal tribe in Rajshahi district, Bangladesh for treatment of various ailments. Afr J Tradit Complement Altern Med 9(3): 350-359.

29. Singh KN, Lal B, Todaria NP (2012) Ethnobotany of higher plants in Spiti Cold Desert of western Himalaya. Nat Sci 10(5): 7-14.

\section{Your next submission with Juniper Publishers will reach you the below assets}

- Quality Editorial service

- Swift Peer Review

- Reprints availability

- E-prints Service

- Manuscript Podcast for convenient understanding

- Global attainment for your research

- Manuscript accessibility in different formats

( Pdf, E-pub, Full Text, Audio)

- Unceasing customer service

Track the below URL for one-step submission

https://juniperpublishers.com/online-submission.php 